\title{
Milk Fatty Acids. I. Variation in the Concentration of Individual Fatty Acids in Bovine Milk
}

\author{
P. J. Moate,${ }^{*}{ }^{1}$ W. Chalupa,${ }^{*}$ R. C. Boston, ${ }^{*}$ and I. J. Lean $\dagger$ \\ ${ }^{*}$ School of Veterinary Medicine, University of Pennsylvania, Kennett Square 19348 \\ †School of Veterinary Science, University of Sydney, New South Wales 2006, Australia
}

\begin{abstract}
Data from 29 published experiments on Holstein cows, providing 120 dietary treatments, were collated to obtain means, standard deviations, and ranges for the concentrations $(\mathrm{mg} / \mathrm{g})$ of 26 major individual fatty acids in bovine milk fat. The influence of diet type (total mixed ration- vs. pasture-based diet) on concentrations of individual fatty acids was examined. Pairwise correlations for concentrations $(\mathrm{g} / \mathrm{kg})$ of individual fatty acids in milk showed that almost all of the individual de novo fatty acids were significantly correlated with each other and with the total concentration of de novo fatty acids. Concentrations of individual unsaturated preformed fatty acids were generally positively correlated with each other but were negatively correlated with concentrations of total de novo fatty acids. Substantial variation was found in the concentrations of individual milk fatty acids and, apart from those synthesized de novo, concentrations of individual fatty acids did not vary in concert. The adequacy of literature data for the development of a model to predict the production of the major individual fatty acids in milk is discussed. The limitations associated with the currently available studies that may be used in a predictive model are 1) failure of many publications to adequately describe dietary details, 2) reporting poorly defined milk fatty acids, 3) aggregating a number of closely related fatty acids under a single category, and 4) the selective reporting of only those fatty acids that are present in milk fat in appreciable quantities. Despite these limitations, the data are sufficient to enable development of a model to predict the concentrations and production of major individual fatty acids in milk fat. The extreme variability in concentrations of individual milk fatty acids and the complex matrix of positive and negative correlations among the concentrations of many individual fatty acids suggest that separate equations will be needed
\end{abstract}

Received March 23, 2007.

Accepted June 28, 2007.

${ }^{1}$ Corresponding author: moate@vet.upenn.edu to predict the production of each individual milk fatty acid.

Key words: milk, fatty acid, concentration

\section{INTRODUCTION}

Milk fat, which is the principal energy component of milk, is almost entirely ( $98 \%)$ composed of triglycerides (Taylor and MacGibbon, 2002). Triglycerides are composed of a glycerol backbone and 3 fatty acids. In the 1980s and early 1990s, a number of excellent reviews were published describing how cow-level factors and feeding practices influenced the fatty acid profiles of milk fat (Sutton, 1989; Grummer, 1991; Jensen et al., 1991; Palmquist et al., 1993).

Milk fat is now known to contain more than 400 individual fatty acids (Jensen, et al., 1991). In recent years, improvements in analytical techniques have facilitated the routine reporting of a large number of the less common geometric and positional isomers of octadecenoic and octadecadienoic acids. The discoveries that cis-9, trans-11 linoleic acid has anticarcinogenic properties (Parodi, 2002), that milk fat depression is specifically associated with an increase in the concentration in milk of the trans-10 18:1 isomer, rather than trans 18:1 isomers in general (Griinari et al., 1998), and that trans10, cis-12 18:2 has potent effects on lowering milk fat concentration when injected or infused postruminally (Parodi, 2002) triggered an explosion of research in this area. During the last $10 \mathrm{yr}$, more than 100 articles have been published that describe the influence of a wide range of nutritional treatments on milk fat yield and composition. These publications have often tabulated fatty acid profiles from 4:0 to 22:6. Fat supplements fed in these experiments have involved a diverse range of traditional fat supplements, including tallow, oilseeds, and fish oil, and some novel or commercial products, including calcium salts of palm oil fatty acids, prilled tallow fatty acids, bioengineered soybeans high in oleic acid, and new varieties of flaxseed high in linolenic acid. Despite these advances, to our knowledge no publication has documented the average concentration or the variability in concentrations of major fatty acids or vari- 
ous isomers of octadecenoic acid and octadecadienoic acid in milk fat. In addition, to our knowledge no statistical or dynamic mathematical model has been developed to predict the influence of dietary and cow-level factors on the profile of major fatty acids in milk fat. Documentation and examination of the means and standard deviations, and correlations of the concentrations of the major fatty acids in milk fat is a necessary starting point for the development of such a model. With respect to the development of a mathematical model, examination of the available literature data enables the adequacy of data to be assessed in terms of its scope, reliability, and accuracy.

The first objective of this paper was to describe how data from the scientific literature were collated into a data set relating how dietary and cow-level factors influence milk fatty acid profiles. It is intended that this data set will be used in a companion paper to describe the development of regression equations to predict the production of 26 major fatty acids in milk fat. A second objective of this paper was to document the mean and variability in concentrations of major individual fatty acids that occur in bovine milk and to examine how concentrations of individual fatty acids in milk fat may vary in relation to the concentrations of other fatty acids.

\section{MATERIALS AND METHODS}

\section{Data Collection}

Data were obtained from original scientific publications. Relevant papers were identified by using computerized searches of CAB Abstracts, PubMed, Medline, and the electronic indices of Journal of Dairy Science and Journal of Dairy Research. Experimental factors and results published in 28 articles (see Table 1) on the influence of diet on milk fat yield and the profile of individual fatty acids were collected and collated. Articles were published between 1992 and 2006 and reported trials were performed in North America ( $\mathrm{n}=$ $20)$, Europe $(n=6)$, and Oceania (Australia and New Zealand; $\mathrm{n}=2$ ). Only papers published since 1992 were included in this analysis, because only in the last 15 yr have many authors included in their articles comprehensive listings of a large number of milk fatty acids (from 4:0 to 22:6). The criteria used for inclusion of an article were that the article had to report the following data: total milk yield (MY, $\mathrm{kg} / \mathrm{d}$ ), total milk fat yield (MF, g/d) or milk fat percentage ( $\mathrm{g} / 100 \mathrm{~g}$ of milk), profile $(\mathrm{g} / 100 \mathrm{~g})$ of individual milk fatty acids, including at least 8:0 to $18: 3$, DIM, total DMI ( $\mathrm{kg} / \mathrm{d})$, total concentration of fatty acids in the diet (FA, g/kg DM), NDF content of the diet ( $\mathrm{g} / \mathrm{kg}$ of DM), CP content of the diet ( $\mathrm{g} /$ $\mathrm{kg}$ of $\mathrm{DM}$ ), and proportions (by DM) of all the major feeds in the diet. Although more than 100 articles were found that contained extensive tabulation of milk fatty acid profiles, many lacked either some or all critical descriptions of dietary factors needed for the development of a predictive model, and these were therefore not included in the database. Articles describing experiments in which milk fat percentage and milk fatty acid composition were influenced by the oral, abomasal, or intravenous administration of mixtures of pharmacological quantities of conjugated linoleic acid (CLA) were excluded from the analysis. Four articles were not included in the database because they listed milk fatty acid profiles that contained obvious and substantial errors.

The 28 articles described a total 29 experiments and 120 dietary treatments (see Table 1). Each article usually described 4 experimental treatments (range 2 to 8 treatments), and there were generally at least 4 cows in each treatment. Cows were usually blocked into groups according to $\mathrm{BW}$, calving date, and preexperimental period milk yield. These groups were then randomly assigned to treatment groups and maintained in controlled conditions during the course of the experiment. Many of the experiments involved Latin square designs in which cows cycled through experimental treatments during the course of the experiment.

Cows in all experiments were Holstein-Friesian. Cows in the experiment by AbuGhazaleh et al. (2003) were primiparous, those in the experiment by Morales et al. (2000) were a mixture of primiparous and multiparous, and those in all other experiments were multiparous. The mean and standard deviation of BW $(\mathrm{kg})$ of cows in each treatment group was $616 \pm 16$, and for DIM, $103 \pm 61$. Cows were fed either a TMR (24 experiment, 102 diets) or were involved in grazing experiments (5 experiments, 18 diets) in which they may also have received dietary supplements. In most experiments, one group of cows received a control diet, and other groups of cows received the control diet plus a substantial amount of a fat supplement. The diets covered a wide range of different types of treatments and supplements. In this database, there were 10 dietary treatment groups that received dietary supplements containing oilseeds; 19 diets containing tallow, grease, or a similar supplement; 11 diets with calcium salts of palm oil fatty acids; 14 diets with plant oils; 6 diets with fish meal; 16 diets with fish oil; and 12 diets in which fatty acids were infused into the abomasum. The average composition of major chemical components in the diets was as follows: NDF, $35.7 \pm 6.4 \%$; $\mathrm{CP}, 17.3 \pm$ $1.8 \%$; total fatty acids as a percentage of $\mathrm{DM}, 4.6 \pm 1.7 \%$.

Treatment means for production data from each publication were entered into an Excel 2006 (Microsoft Corporation, Redmond, WA) spreadsheet. The production 
Table 1. Source of data, main production variables, and dietary treatments in the experiments included in the analysis

\begin{tabular}{|c|c|c|c|c|c|c|}
\hline$\underline{\text { Reference }}$ & $\mathrm{n}^{1}$ & $\begin{array}{l}\mathrm{DMI}, \\
\mathrm{kg} / \mathrm{d}\end{array}$ & $\begin{array}{c}\text { Milk yield, } \\
\text { kg/d }\end{array}$ & $\begin{array}{l}\text { Fatty acid } \\
\text { intake, g/d }\end{array}$ & $\begin{array}{l}\text { Milk fatty } \\
\text { acids, g/d }\end{array}$ & Treatment $^{2}$ \\
\hline AbuGhazaleh et al., 2003 & 4 & $21.8-22.8$ & $28.9-31.7$ & $893-970$ & $693-891$ & $\mathrm{~F}, \mathrm{~T}$ \\
\hline Allred et al., 2006 & 4 & $26.1-28.8$ & $39.1-41.0$ & $1,328-1,794$ & $999-1,242$ & $\mathrm{P}, \mathrm{O}, \mathrm{F}$ \\
\hline Avila et al., 2000 & 4 & $23.9-25.0$ & $32.7-35.3$ & $762-1,263$ & $1,071-1,134$ & $\mathrm{~T}$ \\
\hline Christensen et al., 1994 & 5 & $19.3-22.9$ & $29.4-33.1$ & $772-1,067$ & $846-981$ & In \\
\hline Donovan et al., 2000 & 4 & $20.4-29.0$ & $27.4-34.2$ & $804-1,160$ & $594-837$ & $\mathrm{~F}$ \\
\hline Drackley et al., 1992 & 4 & $22.7-25.1$ & $30.7-33.6$ & $809-1,201$ & $898-1,000$ & In \\
\hline Elliott et al., 1993 & 4 & $23.8-27.2$ & $37.8-42.4$ & $734-2,047$ & $1,044-1,170$ & $\mathrm{~T}$ \\
\hline Enjalbert et al., 2000 & 4 & 18.5 & $21.3-24.5$ & $777-1,256$ & $745-1,028$ & In \\
\hline Gonthier et al., 2005 & 4 & $15.2-15.9$ & $18.0-21.1$ & $557-1,163$ & $585-729$ & $\mathrm{~S}$ \\
\hline Jones et al., 2000 & 4 & $19.7-21.5$ & $30.3-31.6$ & $1,005-1,139$ & $630-729$ & $\mathrm{~F}$ \\
\hline Kay et al., 2004 & 4 & $15.9-16.3$ & $19.9-22.7$ & $636-1,076$ & $747-855$ & $\mathrm{G}, \mathrm{O}$ \\
\hline Kay et al., 2005 & 3 & $16.0-20.0$ & $12.5-19.8$ & $800-920$ & $506-691$ & G \\
\hline Loor et al., 2005a & 4 & $19.6-20.4$ & $24.2-28.8$ & $326-1,040$ & $495-855$ & $\mathrm{O}$ \\
\hline Loor et al., 2005b & 3 & $17.1-19.3$ & $24.4-26.5$ & $701-1,274$ & $621-648$ & $\mathrm{~F}, \mathrm{O}$ \\
\hline Lundy et al., 2004 & 4 & $17.2-20.1$ & $32.0-34.6$ & $1,049-1,142$ & $717-1,163$ & $\mathrm{P}$ \\
\hline Morales et al., 2000 & 4 & $18.1-20.1$ & $27.3-29.3$ & $834-1,095$ & $595-774$ & $\mathrm{~T}, \mathrm{~S}$ \\
\hline Onetti et al., 2004 & 5 & $26.5-27.6$ & $43.6-44.8$ & $1,132-1,347$ & $1,053-1,305$ & $\mathrm{~T}$ \\
\hline Pottier et al., 2006 & 2 & $18.7-18.9$ & $26.3-27.4$ & $1,083-1,092$ & $810-936$ & $\mathrm{O}$ \\
\hline Reveneau et al., 2005 & 5 & $22.2-23.8$ & $39.9-42.7$ & $1,177-1,476$ & $1,020-1,134$ & $\mathrm{G}, \mathrm{S}$ \\
\hline Ruppert et al., 2003 & 6 & $21.4-24.8$ & $32.3-34.2$ & $588-1,260$ & $819-1,053$ & $\mathrm{~T}$ \\
\hline Salawu et al., 2002 & 6 & $14.0-16.5$ & $20.8-23.7$ & $258-355$ & $927-1,066$ & $\mathrm{O}$ \\
\hline Schauff and Clark, 1992 & 4 & $19.6-25.1$ & $31.2-38.1$ & $552-1,646$ & $1,089-1,287$ & $\mathrm{P}$ \\
\hline Schauff et al., 1992 & 4 & $20.0-23.6$ & $33.3-38.1$ & $552-1,740$ & $909-1,116$ & $\mathrm{P}$ \\
\hline Shingfield et al., 2005 & 8 & $19.5-21.0$ & $27.9-28.9$ & $321-403$ & $1,064-1,150$ & $\mathrm{G}$ \\
\hline Tice et al., 1994 & 5 & $16.6-18.2$ & $16.0-19.4$ & $843-1,065$ & $459-567$ & $\mathrm{~S}$ \\
\hline Ward et al., 2002 & 4 & $19.1-20.0$ & $23.3-24.7$ & $732-1,191$ & $837-891$ & $\mathrm{~S}$ \\
\hline Whitlock et al., 2002 & 4 & $21.6-24.5$ & $29.1-34.6$ & $656-1,004$ & $711-1,008$ & $\mathrm{~F}$ \\
\hline Whitlock et al., 2003 & 4 & $26.2-28.7$ & $35.2-37.2$ & $718-783$ & $1,224-1,269$ & $\mathrm{~S}$ \\
\hline
\end{tabular}

${ }^{1} \mathrm{n}=$ number of dietary treatments in each experiment.

${ }^{2}$ Treatments: $\mathrm{G}=$ grazing experiment; $\mathrm{T}=$ tallow or similar fat supplement; $\mathrm{O}=$ oil supplement; $\mathrm{S}=$ oilseeds or high-oil-content corn; $\mathrm{P}=$ protected fatty acid supplement; In = infusion of fatty acids into the abomasum.

data included daily MY, MF, and the profile of milk fatty acids (4:0 to 22:6). Data on each individual milk fatty acid $\left(\mathrm{FA}_{\mathrm{i}}\right)$ was generally reported as grams of $\mathrm{FA}_{\mathrm{i}}$ per $100 \mathrm{~g}$ of total milk fatty acids. A summary of the main production data used in this analysis is shown in Table 1. Across all treatment groups, the production of milk was $30.4 \pm 7.2(\mathrm{~kg} / \mathrm{d})$ and milk fat was $1,011 \pm 235$ $(\mathrm{g} / \mathrm{d})$. The 26 major milk fatty acids that were entered into the spreadsheet included: 4:0 6:0, 8:0, 10:0, 12:0, 14:0, cis-9 14:1, 16:0, cis-9 16:1, C 17 , 18:0, cis-9 18:1, trans 6-8 18:1, trans -9 18:1, trans-10 $18: 1$, trans -11 18:1, trans-12 18:1, cis-9, cis-12 18:2, cis-9, trans-11 18:2, trans-10, cis-12 18:2, other CLA, 18:3, 20:0, 20:5, 22:6, and "other." Various publications reported different fatty acids and possibly had different reporting conventions. For many fatty acids, the exact isomer description was often not reported. In tabulating reported milk fatty acid data in the database, 14:1 was assumed to be $\mathrm{cis}$-9 14:1 unless otherwise indicated, and 16:1 cis was assumed to be cis-9 16:1. Fatty acids with 17 carbon atoms were generally not reported, or sometimes there was no distinction between 17:0 and 17:1 fatty acids. In this analysis, $\mathrm{C}_{17}$ represents the combination of $17: 0$ and 17:1 fatty acids. Frequently, 18:1 was reported with no indication of whether this represented a cis or trans isomer, or a combination of both. In this situation, 18:1 was assumed to represent cis-9 18:1. When 18:1 trans was the only description of trans octadecenoic acid, this was assumed to represent trans-11 18:1. When 18:2 was the only description of octadecadienoic acid, this was assumed to be cis-9, cis-12 18:2, and when 18:3 was reported, this was assumed to be $c i s-9$, cis-12, cis15 18:3. In most publications, the individual milk fatty acids were reported in units of grams per $100 \mathrm{~g}$ of milk fatty acids. In many publications, the total of all the reported fatty acids summed to approximately $93 \mathrm{~g}$, and it was assumed that the approximately 7 -g discrepancy could be described as "other" fatty acids. These "other" fatty acids possibly represented many unidentified acids, such as odd and branched-chain fatty acids, and also positional isomers of some of the more common fatty acids.

Milk fat production ( $\mathrm{g} / \mathrm{d}$ ) was either obtained directly from each publication or calculated from MY and milk fat percentage: 


$$
\mathrm{MF}=\mathrm{MY} \times \text { milk fat percentage } \times 10 .
$$

Milk fat was assumed to contain $93.3 \%$ milk fatty acids (Glasser et al. 2007):

total milk fatty acids $($ PTotalFA, $\mathrm{g} / \mathrm{d})=\mathrm{MF} \times 0.933$.

Production of individual fatty acids $\left(\mathrm{PFA}_{\mathrm{i}}, \mathrm{g} / \mathrm{d}\right)$ was calculated as:

$$
\mathrm{PFA}_{\mathrm{i}}=\mathrm{PTotalFA} \times \mathrm{FA}_{\mathrm{i}} / 100,
$$

where $\mathrm{FA}_{\mathrm{i}}$ is the percentage (wt/wt) of each of the following individual milk fatty acids in the total milk fatty acids: 4:0, 6:0, 8:0, 10:0, 12:0, 14:0, cis-9 14:1, 15:0, 16:0, cis-9 16:1, $\mathrm{C}_{17}, 18: 0$, trans-6-8 18:1, trans-9 18:1, trans10 18:1, trans-11 18:1, trans-12 18:1, cis-9 18:1, cis-9, cis-12 18:2, cis-9, trans-11 18:2, trans-10, cis-12 18:2, other CLA, 18:3, 20:0, 20:5, 22:6, and other. The concentration $(\mathrm{g} / \mathrm{kg})$ of individual fatty acids in milk was calculated as:

$$
\left[\mathrm{FA}_{\mathrm{i}}\right]=\mathrm{PFA}_{\mathrm{i}} / \mathrm{MY}
$$

Fatty acids in bovine milk are considered to be either produced de novo in the mammary gland or derived from plasma lipids. Generally, 4:0 to $14: 0$ and some 16:0 are thought to be produced de novo in the mammary gland (Grummer, 1991). In this investigation, the production of total de novo fatty acids is defined as the sum of the production of 4:0 to 15:0:

$$
\text { total de novo production }(\mathrm{g} / \mathrm{d})=\sum_{\mathrm{i}=4}^{\mathrm{i}=15} \mathrm{PFA}_{\mathrm{i}} \text {. }
$$

Milk fatty acids that are not produced de novo in the mammary gland are often termed "preformed" fatty acids (McGuire and Bauman, 2002). Preformed fatty acids are generally considered to contain some $\mathrm{C}_{16}$ milk fatty acids and milk fatty acids with more than 16 carbon atoms. In this analysis, the term "preformed fatty acids" will be used to signify only fatty acids with more than 16 carbon atoms:

$$
\text { total preformed FA }(\mathrm{g} / \mathrm{d})=\sum_{\mathrm{i}=17}^{\mathrm{i}=22} \mathrm{FA}_{\mathrm{i}} \text {. }
$$

\section{Statistical Analysis}

Simple statistics (means, standard deviations, medians, minima, and maxima) were calculated to describe the concentrations $(\mathrm{mg} / \mathrm{g})$ of the major individual fatty acids in milk fat. Least squares means and standard deviations of the individual fatty acids in milk from cows fed TMR- and pasture-based diets were obtained by means of categorical regressions clustered on experiment. Multiple pairwise correlations using the Bonferroni adjustment were made between concentrations of the major individual fatty acids, groupings of fatty acids, and total milk fat concentration. All statistical analyses were performed with Stata software, version 9 (Stata, 2007).

\section{RESULTS AND DISCUSSION}

A large number of trials contributed to the database used in the project. Although the studies used in the database were recent, there was an unfortunate lack of dietary information in some. Further, some papers did not provide sufficient detail on fatty acid composition to meet the detail required in this study, and assumptions were therefore necessary regarding the composition of some of the milk fatty acids. We acknowledge that these assumptions may have resulted in some slight overestimation of the contribution of the major 18:1, 18:2, and 18:3 fatty acid isomers. Indeed, in considering only $18: 1$, analytical limitations to detection or differentiation may mean that some researchers necessarily had to aggregate a number of octadecenoic fatty acid isomers under 18:1.

\section{Concentrations of Total and Individual Fatty Acids in Milk}

In carrying out this investigation, we had to decide on the most appropriate method of estimating the concentrations of total and individual milk fatty acids in milk fat. Glasser et al. (2007) recently presented a technical note in which they explained that if milk fat is assumed to be composed entirely of triglycerides, then according to their data, milk fat contains $94.4 \pm 0.2 \%$ fatty acids. We repeated their calculations with this data set and obtained a value of $94.6 \pm 0.2 \%$, thus confirming the accuracy of this coefficient and its very small standard deviation. However, Glasser et al. (2007) further refined their calculations to take into account the presence in milk fat of other fatty constituents besides triglycerides. They found that a constant coefficient of 93.3\% was most appropriate to describe the concentration of fatty acids in milk fat; therefore, we adopted the latter coefficient.

A summary of the proportions of 26 major milk fatty acids in the total milk fatty acids (mg/g of total milk fatty acids) from the 120 experimental diets is shown in Table 2. To our knowledge, Table 2 presents the first summarized tabulation of literature data on the concentrations of many of the recently discovered, or 
Table 2. The proportions of 26 individual fatty acids $(\mathrm{mg} / \mathrm{g})$ in the total milk fatty acids from milks described in 28 publications

\begin{tabular}{|c|c|c|c|c|c|}
\hline Fatty acid $^{1}$ & $\mathrm{n}^{2}$ & Mean \pm SD & Median & Minimum & Maximum \\
\hline $4: 0$ & 95 & $31.3 \pm 6.8$ & 29.9 & 18.4 & 49.2 \\
\hline $6: 0$ & 111 & $19.4 \pm 5.2$ & 19.2 & 6.3 & 32.3 \\
\hline $8: 0$ & 111 & $11.7 \pm 3.5$ & 12.0 & 4.8 & 20.9 \\
\hline $10: 0$ & 111 & $24.8 \pm 7.3$ & 25.0 & 10.3 & 39.4 \\
\hline $12: 0$ & 111 & $29.9 \pm 8.5$ & 29.0 & 15.0 & 52.2 \\
\hline $14: 0$ & 111 & $103.8 \pm 17.1$ & 101.7 & 63.3 & 135.0 \\
\hline $14: 1 c 9$ & 101 & $10.8 \pm 3.6$ & 10.9 & 3.5 & 21.3 \\
\hline $15: 0$ & 88 & $10.5 \pm 3.3$ & 10.2 & 4 & 22.6 \\
\hline $16: 0$ & 120 & $285.1 \pm 49.8$ & 281.5 & 147.1 & 462.1 \\
\hline $16: 1 c 9$ & 109 & $17.3 \pm 6.3$ & 17.3 & 4 & 36.5 \\
\hline $\mathrm{C}_{17}$ & 78 & $7.3 \pm 3.5$ & 5.9 & 3.3 & 16.7 \\
\hline 18:0 & 120 & $105.1 \pm 35.9$ & 99.7 & 30.6 & 268.7 \\
\hline $18: 1 t 6-8$ & 33 & $4.6 \pm 2.1$ & 4.9 & 1.2 & 9.6 \\
\hline $18: 1 t 9$ & 37 & $4.4 \pm 2.0$ & 4.4 & 1.4 & 11.4 \\
\hline $18: 1 t 10$ & 30 & $13.1 \pm 15.2$ & 8.1 & 0.3 & 64.7 \\
\hline $18: 1 t 11$ & 90 & $33.3 \pm 21.8$ & 32.6 & 5.8 & 99.5 \\
\hline $18: 1 t 12$ & 19 & $6.5 \pm 3.6$ & 6.3 & 0.9 & 12.7 \\
\hline $18: 1 c 9$ & 120 & $205.0 \pm 53.5$ & 199.6 & 70.3 & 371.4 \\
\hline $18: 2 c 9, c 12$ & 120 & $31.3 \pm 21.1$ & 26.6 & 5.1 & 133.0 \\
\hline $18: 2 c 9, t 11$ & 76 & $10.2 \pm 6.0$ & 8.4 & 2.8 & 24.5 \\
\hline $18: 2 t 10, c 12$ & 35 & $0.4 \pm 0.3$ & .3 & 0 & 1.4 \\
\hline $18: 2 c 11, t 13$ & 6 & $0.4 \pm 0.3$ & 0.3 & 0.2 & 0.9 \\
\hline OCLA & 25 & $1.5 \pm 1.4$ & 1.1 & 0 & 4.2 \\
\hline $18: 3$ & 114 & $5.9 \pm 3.6$ & 4.9 & 0.2 & 19.0 \\
\hline $20: 0$ & 30 & $1.5 \pm 0.6$ & 1.5 & 0.4 & 3.0 \\
\hline $20: 5$ & 39 & $1.0 \pm 1.1$ & 0.5 & 0 & 4.8 \\
\hline $22: 6$ & 31 & $0.7 \pm 0.7$ & 0.4 & 0 & 2.6 \\
\hline Others & 120 & $75.1 \pm 56.2$ & 76.4 & 0 & 237.3 \\
\hline Total CLA & 82 & $10.3 \pm 6.6$ & 8.3 & 3 & 28.4 \\
\hline Total $18: 1$ trans & 94 & $42.5 \pm 26.3$ & 39.5 & 8.6 & 145.1 \\
\hline Total de novo & 120 & $232.6 \pm 42.4$ & 237.9 & 136.6 & 300.6 \\
\hline Total $\mathrm{C}_{16}$ & 120 & $300.9 \pm 52.7$ & 303.0 & 154.2 & 462.1 \\
\hline Total preformed & 120 & $466.5 \pm 75.8$ & 477.4 & 315.6 & 641.3 \\
\hline
\end{tabular}

\footnotetext{
${ }^{1} c=c i s ; t=$ trans OCLA $=$ other conjugated linoleic acids; CLA = conjugated linoleic acid; total 18:1 trans $=$ sum of 18:1t6-8, 18:1t9, 18:1t10,18:1t11, and 18:1t12 isomers; total de novo = sum of 4:0 to 15:0 fatty acids; total $\mathrm{C}_{16}=$ sum of $16: 0$ and $16: 1$; total preformed = sum of all milk fatty acids with more than 17 carbon atoms.

${ }^{2} \mathrm{n}=$ total number of dietary treatments contributing to each mean.
}

only recently routinely reported, positional isomers of many unsaturated fatty acids.

Not all 26 fatty acids were reported in every publication, but more than 100 estimates were available on individual concentrations of $6: 0,8: 0,10: 0,12: 0,14: 0$, cis-9 14:1, 16:0, cis-9 16:1, 18:0, cis-9 18:1, cis-9, cis-12 18:2, and cis-9, cis-12, cis-15 18:3. The concentrations of major milk fatty acids shown in Table 2 are generally consistent with those reported in previous reviews (Jensen et al., 1991; Palmquist et al., 1993). However, 2 interesting discrepancies are the concentrations of 14:1 and 16:1 shown in Table 2, which are approximately $50 \%$ lower than concentrations previously reported by Palmquist et al. (1993) for these fatty acids. This difference may reflect the improved accuracy of analytical methods since 1993. Difficulties in resolving closely related fatty acids determined by using older analytic methods may have led researchers to aggregate a number of fatty acids. Thus, in the older publications $\mathrm{C}_{15}$ was frequently not reported, and during analysis this fatty acid may have been aggregated with cis-9 14:1. We speculate that a similar situation may have occurred with cis-9 16:1 and 17:0. A major finding of this analysis is that for many of the individual fatty acids listed in Table 2, concentrations had standard deviations that ranged from less than $25 \%$ to more than $100 \%$ of the mean values. This high degree of variability highlights the need for equations that predict the influence of diet and other factors on the fatty acid profile of milk fat.

Table 3 summarizes the least squares mean concentrations ( $\mathrm{g} / \mathrm{kg}$ milk) of total and individual fatty acids in the milk of cows fed TMR- and pasture-based diets. Table 3 is somewhat unusual in that the unit of concentration of milk fatty acids is grams per kilogram of milk instead of the more traditional grams per $100 \mathrm{~g}$ of milk fatty acids. We chose to document the fatty acid concentrations in this way because it is an easy unit to concep- 
Table 3. Least squares mean concentrations $(\mathrm{g} / \mathrm{kg})$ of major fatty acids in milk and milk production $(\mathrm{kg} / \mathrm{d})$ from cows fed TMR- or pasture-based diets

\begin{tabular}{|c|c|c|c|c|}
\hline \multirow[b]{2}{*}{ Item $^{1}$} & \multicolumn{2}{|c|}{ TMR } & \multicolumn{2}{|c|}{ Pasture } \\
\hline & $\mathrm{n}^{2}$ & Mean \pm SD & $\mathrm{n}^{2}$ & Mean \pm SD \\
\hline \multicolumn{5}{|l|}{ Fatty acid } \\
\hline $4: 0$ & 77 & $1.02 \pm 0.07$ & 18 & $1.25 \pm 0.19$ \\
\hline $6: 0$ & 93 & $0.66 \pm 0.06$ & 18 & $0.84 \pm 0.13$ \\
\hline 8:0 & 93 & $0.40 \pm 0.04$ & 18 & $0.51 \pm 0.09$ \\
\hline $10: 0$ & 93 & $0.83 \pm 0.07$ & 18 & $1.13 \pm 0.19$ \\
\hline $12: 0$ & 93 & $1.01 \pm 0.09$ & 18 & $1.28 \pm 0.21$ \\
\hline 14:0 & 93 & $3.46 \pm 0.21$ & 18 & $4.53 \pm 0.53$ \\
\hline $14: 1 c 9$ & 83 & $0.36 \pm 0.03$ & 18 & $0.39 \pm 0.07$ \\
\hline $15: 0$ & 75 & $0.33 \pm 0.03$ & 13 & $0.62 \pm 0.09^{* *}$ \\
\hline $16: 0$ & 102 & $9.47 \pm 0.64$ & 18 & $11.81 \pm 1.54$ \\
\hline $16: 1 c 9$ & 91 & $0.58 \pm 0.03$ & 18 & $0.54 \pm 0.11$ \\
\hline $\mathrm{C}_{17}$ & 65 & $0.20 \pm 0.01$ & 13 & $0.61 \pm 0.03 * *$ \\
\hline 18:0 & 102 & $3.44 \pm 0.27$ & 18 & $4.88 \pm 0.55$ \\
\hline $18: 1 t 6-8$ & 32 & $0.14 \pm 0.01$ & $\mathrm{NA}^{3}$ & \\
\hline $18: 1 t 9$ & 36 & $0.13 \pm 0.01$ & NA & \\
\hline $18: 1 t 10$ & 20 & $0.51 \pm 0.14$ & 10 & $0.11 \pm 0.013^{*}$ \\
\hline $18: 1 t 11$ & 72 & $0.93 \pm 0.13$ & 18 & $1.59 \pm 0.07^{* *}$ \\
\hline 18:1t12 & 14 & $0.22 \pm 0.05$ & 5 & $0.19 \pm 0.12$ \\
\hline $18: 1 c 9$ & 102 & $7.08 \pm 0.40$ & 18 & $6.35 \pm 0.37$ \\
\hline $18: 2 c 9, c 12$ & 102 & $1.10 \pm 0.11$ & 18 & $0.58 \pm 0.16^{*}$ \\
\hline $18: 2 c 9, t 11$ & 58 & $0.34 \pm 0.04$ & 18 & $0.27 \pm 0.04$ \\
\hline $18: 2 t 10, c 12$ & 30 & $0.011 \pm 0.002$ & 5 & $0.012 \pm 0.004$ \\
\hline $18: 2 c 11, t 13$ & 6 & $0.011 \pm 0.003$ & NA & \\
\hline OCLA & 25 & $0.042 \pm 0.014$ & NA & \\
\hline $18: 3$ & 96 & $0.20 \pm 0.02$ & 18 & $0.17 \pm 0.03$ \\
\hline $20: 0$ & 18 & $0.043 \pm 0.009$ & 12 & $0.068 \pm 0.002^{*}$ \\
\hline $20: 5$ & 31 & $0.032 \pm 0.006$ & 8 & $0.009 \pm 0.001 *$ \\
\hline $22: 6$ & 31 & $0.018 \pm 0.005$ & NA & \\
\hline Others & 102 & $2.44 \pm 0.34$ & 18 & $2.00 \pm 0.42$ \\
\hline Total CLA & 64 & $0.27 \pm 0.04$ & 18 & $0.34 \pm 0.04$ \\
\hline Total 18:1 trans & 76 & $1.26 \pm 0.14$ & 18 & $1.72 \pm 0.09^{*}$ \\
\hline Total de novo & 102 & $7.62 \pm 0.45$ & 18 & $10.38 \pm 1.52$ \\
\hline Total $\mathrm{C}_{16}$ & 102 & $9.99 \pm 0.66$ & 18 & $12.34 \pm 1.64$ \\
\hline Total preformed & 102 & $15.49 \pm 0.49$ & 18 & $16.46 \pm 1.14$ \\
\hline Total fatty acids & 102 & $33.10 \pm 1.20$ & 18 & $39.18 \pm 3.16$ \\
\hline Milk production & 102 & $30.54 \pm 1.34$ & 18 & $29.31 \pm 3.66$ \\
\hline
\end{tabular}

${ }^{1} c=c i s ; t=$ trans; OCLA = other conjugated linoleic acids; CLA = conjugated linoleic acid; total 18:1 trans $=$ sum of 18:1t6-8, 18:1t9, 18:1t10,18:1t11, and 18:1t12 isomers; total de novo = sum of 4:0 to 15:0 fatty acids; total $\mathrm{C}_{16}=$ sum of $16: 0$ and $16: 1$; total preformed $=$ sum of all milk fatty acids with more than 17 carbon atoms.

${ }^{2} \mathrm{n}=$ total number of dietary treatments contributing to each mean.

${ }^{3} \mathrm{NA}=$ less than 5 data values available.

$* P<0.05 ; * * P<0.01$.

tualize and because it removes the complicating process that occurs with the traditional unit of trying to determine whether a change in the fatty acids in the numerator or denominator resulted in a particular proportion.

Although concentrations of total fatty acids, total de novo fatty acids, total $\mathrm{C}_{16}$, and total preformed fatty acids were all numerically higher in the milk from cows fed pasture-based diets compared with the milk of cows fed TMR-based diets, none of these were statistically higher $(P>0.05)$.

Concentrations of 15:0 and $\mathrm{C}_{17}$ were higher $(P<0.05)$ in milk from cows fed pasture-based rations compared with the concentrations in milk from TMR-fed cows. These findings are consistent with recent findings by
Couvreur et al. (2006), who showed a positive linear relationship between the proportion of fresh grass in the diet and the concentrations of $15: 0$ and $\mathrm{C}_{17}$ fatty acids in milk fat. The estimated mean concentration of total trans-18:1 fatty acids was higher in milk from pasture-fed cows compared with TMR-fed cows, principally because of higher concentrations of trans-11 18:1 in milk from pasture-fed cows. Diet type (pasture- vs. TMR-based diet) also was associated with significant differences in concentrations of a number of other acids, including trans-10 18:1, cis-9, cis-12 18:2, 20:0, and 20:5 $(P<0.05)$.

In Table 3, the least squares mean concentrations of cis-9, trans-11 18:2 in the milk of TMR- and pasture- 
Table 4. Pairwise correlation coefficients between concentrations ( $\mathrm{g} / \mathrm{kg}$ of milk) of individual milk fatty acids or groupings of fatty acids

\begin{tabular}{|c|c|c|c|c|c|c|c|c|c|c|c|}
\hline Fatty acid $^{1}$ & $4: 0$ & $6: 0$ & $8: 0$ & $10: 0$ & $12: 0$ & $14: 0$ & $14: 1$ & $15: 0$ & $16: 0$ & $16: 1$ & $\mathrm{C}_{17}$ \\
\hline $4: 0$ & 1 & & & & & & & & & & \\
\hline $6: 0$ & $0.80 *$ & 1 & & & & & & & & & \\
\hline $8: 0$ & $0.67^{*}$ & $0.95^{*}$ & 1 & & & & & & & & \\
\hline 10:0 & $0.56^{*}$ & $0.87^{*}$ & $0.93 *$ & 1 & & & & & & & \\
\hline 12:0 & $0.49^{*}$ & $0.85^{*}$ & $0.91 *$ & $0.97 *$ & 1 & & & & & & \\
\hline 14:0 & $0.56^{*}$ & $0.86^{*}$ & $0.89 *$ & $0.93 *$ & $0.95^{*}$ & 1 & & & & & \\
\hline $14: 1 c 9$ & 0.28 & $0.55^{*}$ & $0.54 *$ & $0.63 *$ & $0.65^{*}$ & $0.68 *$ & 1 & & & & \\
\hline $15: 0$ & $0.75^{*}$ & $0.71 *$ & $0.64 *$ & $0.68 *$ & $0.64^{*}$ & $0.70^{*}$ & 0.39 & 1 & & & \\
\hline $16: 0$ & $0.58^{*}$ & $0.74^{*}$ & $0.72 *$ & $0.70 *$ & $0.76^{*}$ & $0.85^{*}$ & $0.59 *$ & $0.58 *$ & 1 & & \\
\hline $16: 1 c 9$ & -0.04 & 0.31 & 0.36 & $0.38 *$ & $0.45^{*}$ & $0.45^{*}$ & $0.63 *$ & 0.16 & $0.58 *$ & 1 & \\
\hline $\mathrm{C}_{17}$ & $0.60^{*}$ & $0.51^{*}$ & $0.50 *$ & $0.56^{*}$ & $0.46^{*}$ & $0.61^{*}$ & 0.26 & $0.71 *$ & $0.51^{*}$ & 0.13 & 1 \\
\hline 18:0 & $0.56^{*}$ & $0.55^{*}$ & $0.46^{*}$ & 0.32 & 0.25 & 0.36 & -0.05 & $0.58^{*}$ & 0.33 & -0.29 & $0.51^{*}$ \\
\hline $18: 1 t 6-8$ & -0.59 & -0.59 & -0.62 & -0.65 & $-0.69 *$ & -0.59 & -0.61 & $-0.88^{*}$ & $-0.54^{*}$ & $-0.59 *$ & $-0.67 *$ \\
\hline $18: 1 t 9$ & -0.30 & -0.51 & $-0.68^{*}$ & $-0.71^{*}$ & $-0.75^{*}$ & -0.53 & -0.29 & $-0.74^{*}$ & -0.27 & -0.29 & -0.47 \\
\hline $18: 1 t 10$ & -0.43 & -0.43 & -0.37 & -0.28 & -0.24 & -0.31 & -0.13 & -0.48 & -0.35 & 0.00 & -0.45 \\
\hline $18: 1 t 11$ & -0.22 & -0.30 & -0.26 & -0.22 & -0.27 & -0.17 & -0.43 & -0.01 & -0.16 & -0.13 & $0.71^{*}$ \\
\hline $18: 1 t 12$ & -0.22 & -0.39 & -0.59 & -0.63 & -0.67 & 0.10 & 0.37 & -0.41 & 0.48 & 0.10 & -0.37 \\
\hline $18: 1 c 9$ & 0.31 & 0.30 & 0.26 & 0.07 & 0.06 & 0.11 & 0.04 & -0.02 & 0.26 & 0.01 & -0.03 \\
\hline $18: 2 c 9, c 12$ & -0.04 & -0.22 & -0.16 & -0.13 & -0.14 & -0.24 & -0.17 & -0.46 & -0.25 & -0.24 & -0.41 \\
\hline $18: 2 c 9, t 11$ & -0.24 & -0.35 & -0.36 & $-0.52^{*}$ & $-0.54^{*}$ & $-0.49 *$ & -0.32 & -0.44 & $-0.44^{*}$ & -0.34 & -0.32 \\
\hline $18: 2 t 10, c 12$ & -0.56 & $-0.69 *$ & $-0.69^{*}$ & $-0.68^{*}$ & $-0.66^{*}$ & -0.58 & -0.56 & -0.48 & -0.26 & -0.46 & -0.60 \\
\hline OCLA & -0.68 & 0.06 & -0.02 & -0.09 & -0.18 & -0.17 & -0.29 & -0.65 & -0.46 & -0.53 & -0.44 \\
\hline $18: 3$ & 0.25 & 0.25 & 0.24 & 0.18 & 0.12 & 0.11 & -0.18 & -0.06 & 0.06 & -0.28 & -0.04 \\
\hline 20:0 & 0.57 & 0.49 & 0.45 & 0.45 & 0.45 & 0.55 & 0.12 & 0.49 & 0.50 & -0.09 & 0.59 \\
\hline $20: 5$ & -0.48 & -0.36 & -0.41 & -0.41 & -0.40 & -0.41 & -0.03 & -0.42 & -0.41 & -0.02 & -0.44 \\
\hline $22: 6$ & -0.49 & -0.37 & -0.47 & -0.53 & -0.54 & -0.50 & -0.19 & -0.60 & -0.41 & -0.16 & -0.41 \\
\hline Total 18:1 trans & -0.15 & -0.14 & -0.18 & -0.15 & -0.19 & -0.06 & -0.25 & 0.21 & -0.16 & -0.28 & 0.37 \\
\hline Total de novo & $0.65^{*}$ & $0.89 *$ & $0.90 *$ & $0.95^{*}$ & $0.95^{*}$ & $0.97 *$ & $0.69 *$ & $0.75^{*}$ & $0.79 *$ & 0.33 & $0.66 *$ \\
\hline Total $\mathrm{C}_{16}$ & $0.55^{*}$ & $0.74 *$ & $0.72 *$ & $0.71 *$ & $0.76^{*}$ & $0.85^{*}$ & $0.60 *$ & $0.57 *$ & $0.99 *$ & $0.62^{*}$ & $0.50 *$ \\
\hline Total preformed & $0.43^{*}$ & 0.29 & 0.26 & 0.09 & 0.01 & 0.10 & -0.20 & 0.12 & 0.10 & -0.35 & 0.19 \\
\hline Total milk fat & $0.72^{*}$ & $0.85^{*}$ & $0.83^{*}$ & $0.78 *$ & $0.77^{*}$ & $0.86^{*}$ & $0.51 *$ & $0.69 *$ & $0.85^{*}$ & 0.27 & $0.60 *$ \\
\hline
\end{tabular}

\footnotetext{
${ }^{1} c=c i s ; t=$ trans OCLA $=$ other conjugated linoleic acids; total 18:1 trans $=$ sum of 18:1t6-8, 18:1t9, 18:1t10, $18: 1 t 11$, and $18: 1 t 12$ isomers; total de novo = sum of $4: 0$ to $15: 0$ fatty acids; total $\mathrm{C}_{16}=$ sum of $16: 0$ and 16:1; total preformed = sum of all milk fatty acids with more than 17 carbon atoms.

$* P<0.05$ (multiple correlations with Bonferroni adjustment).
}

fed cows were not significantly different $(P>0.05)$. This may, prima facie, appear surprising because previous research has shown that the concentration of cis-9, trans-11 18:2 is generally higher in milk from pasturefed cows than in milk from TMR-fed cows (Kelly et al., 1998). There are 2 likely explanations for this anomaly. First, the concentration of cis-9, trans-11 18:2 in milk was reported for all 18 of the pasture-based rations, whereas it was reported for only 58 of the 102 TMRbased rations. We speculate that nonreporting (reporting bias) of the concentration of cis-9, trans-11 18:2 probably occurred if the concentration of cis-9, trans11 18:2 was very low or, indeed, if cis-9, trans-11 18:2 was not detected. Second, fish oil, a supplement known to enhance cis-9, trans-11 18:2 concentrations in milk (AbuGhazaleh et al., 2003), was not included in any of the 18 pasture-based diets but was included in 20 of the 58 TMR rations for which the concentration of cis9, trans-11 18:2 was reported. Further, fish oil was not included in any of the 44 TMR diets for which the concentration of cis-9, trans-11 18:2 was not reported. Thus, with respect to TMR diets, the mean concentra- tions of cis-9, trans-11 18:2 shown in Table 3 may well be overestimated. We further speculate that a similar reporting bias may influence means for many of the fatty acids in Tables 2 and 3, especially in cases in which substantially fewer than the maximal number of observations contributed to a mean. Despite the limitations of the database and differences in concentrations of some minor isomers of fatty acids, the means shown in Table 2 are consistent with data presented in previous reviews, in which it has been shown that the concentrations of major individual fatty acids in bulk milk fat from Australian cows, where grazing is the dominant dairy production system, are generally similar to those in bulk milk fat from US cows, which are predominantly fed TMR rations (Jensen et al., 1991). The data set in this investigation included some studies in which extreme quantities of fat supplements and unusual types of fat supplements were fed. Thus, in Table 2, the minima and maxima for concentrations of individual fatty acids must be regarded as being outside the limits of what could be considered normal milk. 
Table 5. Pairwise correlation coefficients between concentrations ( $\mathrm{g} / \mathrm{kg}$ of milk) of individual milk fatty acids or groupings of fatty acids ${ }^{1}$

\begin{tabular}{|c|c|c|c|c|c|c|c|c|c|c|c|}
\hline \multirow[b]{2}{*}{ Fatty acid } & \multicolumn{6}{|c|}{$\mathrm{C}_{18}$ monounsaturated } & \multicolumn{5}{|c|}{$\mathrm{C}_{18}$ diene } \\
\hline & $18: 0$ & $t 68$ & $t 9$ & $t 10$ & $t 11$ & $t 12$ & $c 9$ & $c 9, c 12$ & $c 9, t 11$ & $t 10, c 12$ & OCLA \\
\hline 18:0 & 1 & & & & & & & & & & \\
\hline $18: 1 t 6-8$ & 0.12 & 1 & & & & & & & & & \\
\hline $18: 1 t 9$ & 0.05 & $0.77^{*}$ & 1 & & & & & & & & \\
\hline $18: 1 t 10$ & -0.35 & 0.48 & 0.31 & 1 & & & & & & & \\
\hline $18: 1 t 11$ & 0.08 & 0.46 & 0.51 & -0.04 & 1 & & & & & & \\
\hline 18:1t12 & 0.05 & 0.18 & 0.69 & 0.06 & 0.06 & 1 & & & & & \\
\hline $18: 1 c 9$ & $0.53^{*}$ & 0.01 & 0.00 & -0.35 & -0.14 & 0.45 & 1 & & & & \\
\hline $18: 2 c 9, c 12$ & -0.17 & -0.02 & -0.15 & 0.02 & -0.17 & 0.03 & 0.16 & 1 & & & \\
\hline $18: 2 c 9, t 11$ & 0.05 & 0.47 & 0.51 & 0.29 & 0.41 & 0.33 & 0.24 & 0.03 & 1 & & \\
\hline $18: 2 t 10, c 12$ & 0.12 & $0.77^{*}$ & $0.70^{*}$ & 0.48 & $0.62 *$ & 0.55 & 0.12 & 0.23 & 0.42 & 1 & \\
\hline OCLA & 0.09 & 0.64 & 0.45 & 0.48 & 0.15 & $0.97^{*}$ & -0.23 & -0.46 & 0.63 & 0.04 & 1 \\
\hline $18: 3$ & 0.30 & 0.12 & -0.11 & -0.02 & -0.13 & 0.16 & 0.25 & 0.20 & 0.42 & -0.17 & 0.51 \\
\hline $20: 0$ & 0.52 & 0.08 & 0.44 & -0.16 & 0.39 & 0.00 & -0.19 & -0.46 & -0.49 & 0.23 & -0.14 \\
\hline $20: 5$ & $-0.71^{*}$ & 0.02 & 0.35 & 0.49 & -0.03 & 0.09 & $-0.71^{*}$ & -0.17 & 0.47 & -0.19 & 0.37 \\
\hline $22: 6$ & -0.38 & 0.38 & $0.63^{*}$ & 0.12 & 0.07 & 0.31 & -0.43 & -0.35 & 0.36 & 0.16 & 0.38 \\
\hline Total 18:1 trans & 0.20 & $0.68^{*}$ & $0.51^{*}$ & $0.67^{*}$ & $0.75^{*}$ & 0.35 & -0.22 & $-0.38^{*}$ & $0.56^{*}$ & $0.65^{*}$ & 0.59 \\
\hline Total de novo & $0.41^{*}$ & $-0.73^{*}$ & $-0.63^{*}$ & -0.39 & -0.20 & -0.22 & 0.16 & -0.19 & $-0.44^{*}$ & $-0.65^{*}$ & -0.22 \\
\hline Total $\mathrm{C}_{16}$ & 0.31 & $-0.55^{*}$ & -0.25 & -0.34 & -0.14 & 0.48 & 0.26 & -0.26 & -0.43 & $-0.65^{*}$ & -0.46 \\
\hline Total preformed & $0.69 *$ & 0.26 & 0.11 & -0.31 & 0.07 & 0.35 & $0.76^{*}$ & 0.15 & 0.36 & 0.20 & 0.25 \\
\hline Total milk fat & $0.61^{*}$ & $-0.42^{*}$ & -0.28 & $-0.43^{*}$ & -0.14 & 0.29 & $0.52 *$ & -0.14 & -0.24 & $-0.37^{*}$ & -0.31 \\
\hline
\end{tabular}

${ }^{1} c=c i s ; t=$ trans; OCLA $=$ other conjugated linoleic acids; total 18:1 trans = sum of 18:1t6-8, 18:1t9, $18: 1 t 10,18: 1 t 11$, and $18: 1 t 12$ isomers; total de novo = sum of $4: 0$ to $15: 0$ fatty acids; total $\mathrm{C}_{16}=$ sum of $16: 0$ and 16:1; total preformed $=$ sum of all milk fatty acids with more than 17 carbon atoms.

$* P<0.05$ (multiple correlations with Bonferroni adjustment)

We consider that the consistency of milk fat concentrations under different feeding conditions and the wide range of diets used in the studies that form this database strongly support the validity of models potentially derived from this study. Further, the consistency of findings between grazing and TMR diets suggests that a single model may be able to describe milk fat profiles for grazing cows and cows fed TMR diets.

The scientific literature seems to contain only limited reports on pairwise correlations of the major fatty acids in milk fat (Karijord et al., 1982; Soyeurt et al., 2006). Tables 4, 5, and 6 present pairwise correlations of the concentrations of 26 of the major individual fatty acids and groupings of fatty acids in milk. The major difference between our findings and those of earlier researchers is that we report the correlation coefficients of many more fatty acids, especially the various isomers of unsaturated $\mathrm{C}_{18}$ fatty acids. The magnitude of the correlations shown in Tables 4, 5, and 6 may differ somewhat from those estimated by Karijord et al. (1982) and Soyeurt et al. (2006), but our findings support the direction of individual associations reported by earlier researchers.

Concentrations of almost all the de novo fatty acids (4:0 to $15: 0)$ were strongly $(P<0.05)$ positively correlated with each other, with the concentration of total de novo fatty acids, and with total milk fat concentration (Table 4). The concentration of $16: 0$, which is generally the fatty acid present in milk at the highest concentra- tion, was also $(P<0.05)$ positively correlated with all but one of the individual de novo fatty acids, with total de novo fatty acids, with cis-9 16:1, with $\mathrm{C}_{17}$, and with total milk fat concentrations, but was not correlated with the total concentration of preformed fatty acids. The concentration of 18:0 was positively correlated ( $P$ $<0.05$ ) with 4:0, 6:0, 8:0, 15:0, 17:0, cis-9 18:1, 20:0, total de novo fatty acids, total preformed fatty acids, and total milk fat concentration (Tables 4, 5, and 6). The positive correlation between the concentrations of 18:0 and cis-9 18:1 probably reflects the fact that cis-9

Table 6. Pairwise correlation coefficients between concentrations (g/ $\mathrm{kg}$ of milk) of individual milk fatty acids or groupings of fatty acids

\begin{tabular}{|c|c|c|c|c|}
\hline Fatty acid ${ }^{1}$ & $18: 3$ & $20: 0$ & $20: 5$ & $22: 6$ \\
\hline $18: 3$ & 1 & & & \\
\hline $20: 0$ & 0.11 & 1 & & \\
\hline $20: 5$ & -0.29 & 0.09 & 1 & \\
\hline $22: 6$ & 0.00 & $0.71^{*}$ & 0.63 & 1 \\
\hline Total CLA & 0.17 & -0.09 & 0.46 & 0.40 \\
\hline Total 18:1 trans & 0.00 & 0.32 & 0.21 & 0.31 \\
\hline Total de novo & 0.16 & $0.56^{*}$ & -0.33 & -0.26 \\
\hline Total $\mathrm{C}_{16}$ & 0.05 & $0.49 *$ & -0.39 & -0.39 \\
\hline Total preformed & $0.44^{*}$ & 0.21 & $-0.47^{*}$ & -0.12 \\
\hline Total milk fat & 0.31 & $0.55^{*}$ & $-0.46^{*}$ & -0.35 \\
\hline
\end{tabular}

${ }^{1} c=c i s ; t=$ trans $;$ CLA = conjugated linoleic acid; total 18:1 trans $=$ sum of $18: 1 t 6-8,18: 1 t 9,18: 1 t 10,18: 1 t 11$, and 18:1t12 isomers; total de novo $=$ sum of 4:0 to 15:0 fatty acids; total $C_{16}=$ sum of 16:0 and 16:1; total preformed $=$ sum of all milk fatty acids with more than 17 carbon atoms.

$* P<0.05$ (multiple correlations with Bonferroni adjustment). 
18:1 is produced in the mammary gland by the action of the $\Delta^{9}$-desaturase enzyme working on 18:0. Another finding that supports the general conclusions made by Karijord et al. (1982) is that concentrations of individual unsaturated preformed fatty acids were generally positively correlated $(P<0.05)$ with each other but negatively correlated $(P<0.05)$ with the concentration of total de novo fatty acids (Table 5).

We note that the concentration of cis-9 18:1 was negatively correlated $(P<0.05)$ with the concentration of $20: 5$, which suggests that $20: 5$ might in some way inhibit the $\Delta^{9}$-desaturation reaction (Table 5 ). Tables 4 , 5 , and 6 show a number of positive and negative $(P<$ 0.05 ) correlations among the various individual fatty acids. These correlations no doubt reflect many biological and chemical processes, which include absorption of fatty acids from the intestines and transformation reactions within the mammary gland (e.g., isomerization). The negative correlations of trans-10 18:1 with total milk fat concentration and of trans-10, cis-12 18:2 with total milk fat concentration are not surprising because these negative associations have been well documented previously (Bauman and Griinari, 2003).

Fish oil feed supplements are well known for their propensity to induce milk fat depression (Bauman and Griinari, 2003). As shown in Table 6, the only major fish oil fatty acid that was negatively correlated $(P<$ 0.05 ) with total milk fat concentration was 20:5. Further, there were no significant positive correlations between 20:0, 20:5 and 20:6 and either trans-10 18:1 or trans-10, cis-12 18:2, 2 fatty acids that have been associated with low milk fat concentration. This observation suggests that 20:5 per se may be the principal fish oil fatty acid associated with low milk fat concentration. The multiple significant correlations shown in Tables 4,5 , and 6 provide much information that allows speculation, but causal relationships between individual milk fatty acid isomers and milk fat concentration will only be established with subsequent experimentation. Nevertheless, Tables 4, 5, and 6 show that some milk fatty acids are positively correlated both with others and with concentrations of total milk fat, whereas other fatty acids are negatively correlated with each other and with the concentration of total milk fat.

\section{CONCLUSIONS}

This analysis documents, for the first time, mean concentrations and variability of the 26 major fatty acids in bovine milk fat. Overall, the data presented in Tables 2 and 3 show that the concentrations of individual fatty acids in milk can vary substantially. Critical examination of the data indicates that a number of aspects influence the usefulness of these data for model- building purposes. The primary limitation is that in many publications, the description of some fatty acids is poor and acronyms are used for groupings of fatty acids instead of specific fatty acids. Another limitation is in reporting some minor fatty acids, especially various isomers of octadecanoic and octadecadienoic acid. We consider that average literature concentrations of many minor fatty acids may be overestimated because of selective or biased reporting. Despite these limitations, the extensive data tabulated and the wide range of basal and experimental diets used in the studies suggest that sufficient data are available to enable the development of empirical equations to predict concentrations and daily production of major individual fatty acids in milk fat. The positive and negative correlations $(P<0.05)$ found among many individual fatty acids and groupings of fatty acids suggest that the concentrations of individual milk fatty acids are not similarly influenced by various dietary or animal factors. The fact that concentrations of all the individual de novo fatty acids are correlated with each other and with the concentration of total de novo fatty acids suggest that a common predictive equation may be able to explain much of the variation in the production of these fatty acids. The complex matrix of positive and negative correlations among the individual preformed fatty acids suggests that individual equations may be needed to predict how dietary and animal factors influence their production.

\section{REFERENCES}

AbuGhazaleh, A. A., D. J. Schingoethe, A. R. Hippen, and K. F. Kalscheur. 2003. Conjugated linoleic acid and vaccenic acid in rumen, plasma, and milk of cows fed fish oil and fats differing in saturation of 18 carbon fatty acids. J. Dairy Sci. 86:3648-3660.

Allred, S. L., T. R. Dhiman, C. P. Brennand, R. C. Khanal, D. J. McMahon, and N. D. Luchini. 2006. Milk and cheese from cows fed calcium salts of palm and fish oil alone or in combination with soybean products. J. Dairy Sci. 89:234-248.

Avila, C. D., E. J. DePeters, H. Perez-Monti, S. J. Taylor, and R. A. Zinn. 2000. Influences of saturation ratio of supplemental dietary fat on digestion and milk yield in dairy cows. J. Dairy Sci. 83:1505-1519.

Bauman, D. E., and J. M. Griinari. 2003. Nutritional regulation of milk fat synthesis. Annu. Rev. Nutr. 23:203-227.

Christensen, R. A., J. K. Drackley, D. W. LaCount, and J. H. Clark. 1994. Infusion of four long-chain fatty acid mixtures into the abomasum of lactating dairy cows. J. Dairy Sci. 77:1052-1069.

Couvreur, S., C. Hurtaud, C. Lopez, L. DeLaby, and J. L. Peyraud. 2006. The linear relationship between the proportion of fresh grass in the cow diet, milk fatty acid composition, and butter properties. J. Dairy Sci. 89:1956-1969.

Donovan, D. C., D. J. Schingoethe, R. J. Baer, J. Ryali, A. R. Hippen, and S. T. Franklin. 2000. Influence of dietary fish oil on conjugated linoleic acid and other fatty acids in milk fat from lactating dairy cows. J. Dairy Sci. 83:2620-2628.

Drackley, J. K., T. H. Klusmeyer, A. M. Trusk, and J. H. Clark. 1992. Infusion of long-chain fatty acids varying in saturation and chain length into the abomasum of lactating dairy cows. J. Dairy Sci. 75:1517-1526. 
Elliott, J. P., J. K. Drackley, D. J. Schauff, and E. H. Jaster. 1993. Diets containing high oil corn and tallow for dairy cows during early lactation. J. Dairy Sci. 76:775-789.

Enjalbert, F., M. C. Nicot, C. Bayourthe, and R. Moncoulon. 2000. Effects of duodenal infusions of palmitic, stearic, or oleic acids on milk composition and physical properties of butter. J. Dairy Sci. 83:1428-1433.

Glasser, F., M. Doreau, A. Ferlay, and Y. Chilliard. 2007. Technical note: Estimation of milk fatty acid yield from milk fat data. J. Dairy Sci. 90:2302-2304.

Gonthier, C., A. F. Mustafa, D. R. Ouellet, P. Y. Chouinard, R. Berthiaume, and H. V. Petit. 2005. Feeding micronized and extruded flaxseed to dairy cows: effects on blood parameters and milk fatty acid composition. J. Dairy Sci. 88:748-756.

Griinari, J. M., D. A. Dwyer, M. A. McGuire, D. E. Bauman, D. L. Palmquist, and K. V. Nurmela. 1998. Trans-octadecenoic acids and milk fat depression in lactating dairy cows. J. Dairy Sci. 81:1251-1261.

Grummer, R. R. 1991. Effect of feed on the composition of milk fat. J. Dairy Sci. 74:3244-3257.

Jensen, R. G., A. M. Ferris, and C. J. Lammi-Keefe. 1991. The composition of milk fat. J. Dairy Sci. 74:3228-3243.

Jones, D. F., W. P. Weiss, and D. L. Palmquist. 2000. Short communication: influence of dietary tallow and fish oil on milk fat composition. J. Dairy Sci. 83:2024-2026.

Kay, J. K., T. R. Mackle, M. J. Auldist, N. A. Thomson, and D. E. Bauman. 2004. Endogenous synthesis of cis-9, trans-11 conjugated linoleic acid in dairy cows fed fresh pasture. J. Dairy Sci. 87:369-378.

Kay, J. K., J. R. Roche, E. S. Kolver, N. A. Thomson, and L. H. Baumgard. 2005. A comparison between feeding systems (pasture and TMR) and the effect of vitamin $\mathrm{E}$ supplementation on plasma and milk fatty acid profiles in dairy cows. J. Dairy Res. 72:322-332.

Karijord, Ø., N. Standal, and O. Syrstad. 1982. Sources of variation in composition of milk fat. Z. Tierz. Zuectungsbiol. 99:81-91.

Kelly, M. L., E. S. Kolver, D. E. Bauman, M. E. Van Amburgh, and L. D. Muller. 1998. Effect of intake of pasture on concentrations of conjugated linoleic acid in milk of lactating cows. J. Dairy Sci. 81:1630-1636.

Loor, J. J., A. Ferlay, A. Ollier, M. Doreau, and Y. Chilliard. 2005a. Relationship among trans and conjugated fatty acids and bovine milk fat yield due to dietary concentrate and linseed oil. J. Dairy Sci. 88:726-740.

Loor, J. J., A. Ferlay, A. Ollier, K. Ueda, M. Doreau, and Y. Chilliard. 2005b. High-concentrate diets and polyunsaturated oils alter trans and conjugated isomers in bovine rumen, blood, and milk. J. Dairy Sci. 88:3986-3999.

Lundy, F. P., E. Block, W. C. Bridges, Jr., J. A. Bertrand, and T. C. Jenkins. 2004. Ruminal biohydrogenation in Holstein cows fed soybean fatty acids as amides or calcium salts. J. Dairy Sci. 87:1038-1046

McGuire, M. A., and D. E. Bauman. 2002. Milk biosynthesis and secretion. Pages 1826-1834 in Encyclopedia of Dairy Science. Vol. 3. H. Roginski, J. Fuquay, and P. Fox, ed. Elsevier Science Ltd., London, UK.

Morales, M. S., D. L. Palmquist, and W. P. Weiss. 2000. Effects of fat source and copper on unsaturation of blood and milk triacyl- glycerol fatty acids in Holstein and Jersey cows. J. Dairy Sci. 83:2105-2111.

Onetti, S. G., S. M. Reynal, and R. R. Grummer. 2004. Effect of alfalfa forage preservation method and particle length on performance of dairy cows fed corn silage-based diets and tallow. J. Dairy Sci. 87:652-664.

Palmquist, D. L., A. D. Beaulieu, and D. M. Barbano. 1993. Feed and animal factors influencing milk fat composition. J. Dairy Sci. $76: 1753-1771$.

Parodi, P. W. 2002. Conjugated linoleic acid. Pages 1587-1594 in Encyclopedia of Dairy Sciences. H. Roginski, J. W. Fuquay, and P. F. Fox, ed. Elsevier Science Ltd., London, UK.

Pottier, J., M. Focant, C. Debier, G. De Buysser, C. Goffe, E. Mignolet, E. Froidmont, and Y. Larondelle. 2006. Effect of dietary vitamin $\mathrm{E}$ on rumen biohydrogenation pathways and milk fat depression in dairy cows fed high-fat diets. J. Dairy Sci. 89:685-692.

Reveneau, C., C. V. Ribeiro, M. L. Eastridge, N. R. St-Pierre, and J. L. Firkins. 2005. Processing whole cottonseed moderates fatty acid metabolism and improves performance by dairy cows. J. Dairy Sci. 88:4342-4355.

Ruppert, L. D., J. K. Drackley, D. R. Bremmer, and J. H. Clark. 2003. Effects of tallow in diets based on corn silage or alfalfa silage on digestion and nutrient use by lactating dairy cows. J. Dairy Sci. 86:593-609.

Salawu, M. B., A. T. Adesogan, and R. J. Dewhurst. 2002. Forage intake, meal patterns, and milk production of lactating dairy cows fed grass silage or pea-wheat bi-crop silages. J. Dairy Sci. 85:3035-3044.

Schauff, D. J., and J. H. Clark. 1992. Effects of feeding diets containing calcium salts of long-chain fatty acids to lactating dairy cows. J. Dairy Sci. 75:2990-3002.

Schauff, D. J., J. H. Clark, and J. K. Drackley. 1992. Effects of feeding lactating dairy cows diets containing extruded soybeans and calcium salts of long-chain fatty acids. J. Dairy Sci. 75:3003-3019.

Soyeurt, H., P. Dardenne, A. Gillon, C. Croquet, S. Vanderick, P. Mayeres, C. Bertozzi, and N. Gengler. 2006. Variation in fatty acid contents of milk and milk fat within and across breeds. J. Dairy Sci. 89:4858-4865.

Stata. 2007. Stata Statistical Software. Release 9.0. Stata Corp., College Station, TX

Sutton, J. D. 1989. Altering milk composition by feeding. J. Dairy Sci. 72:2801-2814.

Taylor, M. W., and A. K. H. MacGibbon, eds. 2002. Triaglycerols. Vol. 3. Elsevier Science Ltd., London, UK

Tice, E. M., M. L. Eastridge, and J. L. Firkins. 1994. Raw soybeans and roasted soybeans of different particle sizes. 2. Fatty acid utilization by lactating cows. J. Dairy Sci. 77:166-180.

Ward, A. T., K. M. Wittenberg, and R. Przybylski. 2002. Bovine milk fatty acid profiles produced by feeding diets containing solin, flax and canola. J. Dairy Sci. 85:1191-1196.

Whitlock, L. A., D. J. Schingoethe, A. R. Hippen, K. F. Kalscheur, and A. A. Abughazaleh. 2003. Milk production and composition from cows fed high oil or conventional corn at two forage concentrations. J. Dairy Sci. 86:2428-2437.

Whitlock, L. A., D. J. Schingoethe, A. R. Hippen, K. F. Kalscheur, R. J. Baer, N. Ramaswamy, and K. M. Kasperson. 2002. Fish oil and extruded soybeans fed in combination increase conjugated linoleic acids in milk of dairy cows more than when fed separately. J. Dairy Sci. 85:234-243. 